\title{
UNA CALA EN LAS MOJIGANGAS DE CALDERÓN. TEXTO Y REPRESENTACIÓN
}

\author{
Aurelio González \\ Centro de Estudios Lingüísticos y Literarios \\ El Colegio de México A. C. \\ Camino al Ajusco 20 \\ Col. Pedregal de Sta. Teresa \\ C.P. 10740 \\ D. F. México \\ agonza@colmex.mx
}

[Anuario calderoniano (ISSN: 1888-8046), 7, 2014, pp. 149-165]

En diversas ocasiones se ha hablado de la relación de la mojiganga con el carnaval y se ha planteado que la mojiganga "es una forma dramática en la que cristaliza por estilización, y según los procesos estéticos según los cuales un hecho cotidiano se transforma en obra artística, el fenómeno más amplio de la actividad popular carnavalesca» ${ }^{1}$. O sea, a pesar de toda la subversión o irreverencia que puede implicar el Carnaval y las posiciones extremas de burla y parodia que puede asumir, en el momento de su integración a un modelo dramático (en especial al del teatro breve de los Siglos de Oro) la

${ }^{1}$ Rodríguez y Tordera, 1983, p. 59. 
estructuración teatral se vuelve dominante y las características que definen a la mojiganga teatral serán las del espectáculo y la textualidad (por encima de la intención de subversión o de la misma parodia). Pero tampoco hay que olvidar que la risa se genera con mayor facilidad y es más apreciada cuando se genera en el borde de lo prohibido e irreverente. Tal vez por esto se ha relacionado frecuentemente a los géneros teatrales cómicos breves con el Carnaval ${ }^{2}$. Estas características de teatralidad de la mojiganga se extienden a los otros géneros breves como la jácara, el entremés o el baile, imposibilitando, como ya se ha dicho muchas veces, trazar fronteras precisas, en nuestro caso, entre la mojiganga y los diversos subgéneros cómicos breves.

A pesar de la imprecisión o difuminación de las características teatrales específicas de la mojiganga, sí se pueden mencionar algunos elementos referenciales o "paradigmas» de los que parte la composición dramática de este género de obras. Estos referentes son: la corporalidad, la naturaleza, la transformación y la suspensión del tiempo ${ }^{3}$. En un sentido podríamos decir que lo que hace la mojiganga es llevar al extremo elementos generales del teatro cómico breve, así, la corporalidad puede terminar por ser escatológica, la naturaleza implica la vivificación de lo inanimado y la presencia de apariencias grotescas y ridículas; el principio de la transformación hace que los temas graves o incluso pesarosos puedan volverse ridículos y burlescos y, finalmente, la suspensión de la temporalidad hace que en el escenario exista una continuidad ininterrumpida del tiempo de lo real con el tiempo de lo extravagante y ficcional, esto es, a partir de un simple elemento de verosimilitud la obra puede derivar a la exageración casi farsesca y la ubicación casi maravillosa. Así, dentro de su aparente sencillez y simplicidad, estas obras implican una maestría para su composición, sobre todo por el poco desarrollo dramático que pueden tener, por su brevedad, las situaciones, personajes, referencias, etc.

${ }^{2}$ La existencia de elementos carnavalescos en el teatro cómico breve ya fue señalada en el trabajo señero de Eugenio Asensio (1971). Más recientemente y más ampliamente ha sido estudiada la locura festiva en el teatro breve por Huerta Calvo,1995, pp. 135-155. Ver el trabajo de Catalina Buezo (2004) considerando el teatro breve como una práctica festiva que pasaba del ámbito de la fiesta al escenario. Sobre la mojiganga es trabajo obligado el de Buezo (1993).

${ }^{3}$ Sobre estos paradigmas ver Rodríguez y Tordera, 1983, pp. 63-67. 
Esto explica la existencia de autores "profesionales» del teatro breve como Quiñones de Benavente y la distancia que tomaban de los géneros cómicos breves algunos grandes dramaturgos como Lope de Vega o Ruiz de Alarcón. Pero también otros autores de comedias notables se desempeñaban con comodidad en esta comicidad breve, como Moreto, y baste recordar que algunos críticos el único mérito teatral que le reconocen a Cervantes, a pesar de haber escrito dramas y comedias, es en los entremeses. Por su parte Calderón posiblemente haya sido el del espectro teatral más amplio, pues su prestigio en los autos sacramentales está fuera de toda duda, así como su capacidad en la comedia y el drama, sin olvidar sus espectáculos mitológicos palaciegos, pero también en el teatro breve destacó escribiendo, según Vera Tassis, cien sainetes o entremeses, aunque poco ha llegado a nosotros de esa cantidad. Hartzenbusch en el siglo XIX publica catorce obras; en 1983 Evangelina Rodríguez y Antonio Tordera publican 24 (diecisiete entremeses, dos jácaras y cinco mojigangas), y poco tiempo después (1989) María Luisa Lobato publica o da noticia de 59, aunque hay muchas más que se descubren o atribuyen con más o menos certeza ${ }^{4}$. Calderón manejaba en estas pequeñas obras cómicas los mismos elementos de estructuración dramática y rigor que utilizaba en sus autos sacramentales, comedias o dramas. Esto es, el texto, la palabra hablada como principio nuclear o generador del espectáculo, el cual se realizaba visual y corpóreamente en escena en una cadena sígnica de relaciones de significados y significantes en una tensión dinámica y dialéctica, de acuerdo a las convenciones teatrales de su tiempo.

Tradicionalmente son cinco las mojigangas más conocidas compuestas por Calderón ${ }^{5}$ : Los sitios de recreación del Rey (recogida originalmente en Tardes apacibles de gustoso entretenimiento, repartidas en varios entremeses y bailes entremesados escogidos de los mejores ingenios de España, 1663); El pésame de la viuda (en la Primera parte del Parnaso Nuevo y amenidades del gusto en veinte $y$ ocho entremeses, bailes y sainetes. De los

${ }^{4}$ Para los problemas textuales de este corpus entremesil calderoniano ver Arellano, 2013.

5 Así lo asumen tanto la edición de Evangelina Rodríguez y Antonio Tordera (1982) como la de María Luisa Lobato (1989). Posteriormente se han ido encontrando más textos que pueden ser atribuidos a Calderón, por ejemplo, Agustín de la Granja (1987) presenta una más: la Mojiganga del Parnaso y Fernando Plata (2009) la Mojiganga del mundinovo o las de Juan Rana. 
mejores ingenios de España, 1670); Las visiones de la muerte (en el Ms 16.796 BN, del siglo XVII, y en las Flores del Parnaso, cogidas para recreo del entendimiento por los mejores ingenios de España en loas, entremeses $y$ mojigangas, 1708); La garapiña (Ms. 15.652 BNE, siglo XVII) y Los guisados (Ms. 16.427 BNE, finales siglo XVII). En un trabajo anterior me he referido a la comicidad escénica de La garapiña ${ }^{6}$; en esta ocasión me centraré en Las visiones de la muerte, El pésame de la viuda y Los guisados tomando en cuenta la experiencia de haberlas llevado a la escena a finales de $2011^{7}$.

Como se sabe, estas piezas cortas, aunque son autónomas, fueron concebidas para ser representadas en un espectáculo complejo con obras de otro tipo. Así, la mojiganga de El pésame de la viuda posiblemente haya sido escrita para acompañar los autos sacramentales de 1662 (Las pruebas del segundo Adán o Mística y Real Babilonia) ${ }^{8}$ o de 1664 (La inmunidad del sagrado) ${ }^{9}$. Esta última fecha también es posible para Los guisados y para acompañar el auto $A$ María el corazón $n^{10}$. Por el contrario, Las visiones de la muerte parece haber sido compuesta para el auto La vida es sueño de $1673^{11}$, aunque otros suponen que fue para el auto El pleito matrimonial del Cuerpo y el Alma de $1652^{12}$.

Aunque el teatro áureo es un teatro de fórmula, la capacidad creativa hacía que las obras revisaran y potenciaran esa fórmula en múltiples posibilidades. Las tres mojigangas de Calderón a las que nos hemos referido corresponden a distintos tipos de estructura cómica de acuerdo a una organización particular de contenidos temáticos. Así Las visiones de la muerte se acerca más a contenidos que son tradicionales o del folclor. La imagen del caminante medio borracho que cree ver visiones cuando que se trata simplemente del accidente de un carro que transporta una compañía teatral. En esta mojiganga la parodia será una línea que avanza a lo largo de toda la pieza. Hay parodia del per-

6 González, 2010.

7 Montaje del espectáculo Mojiganga con el grupo TECA (Teatro Experimental del Centro Asturiano) que dio funciones durante los meses de octubre y noviembre de 2011.

${ }^{8}$ Rodríguez y Tordera, 1983, p. 165.

${ }^{9}$ Granja, 1982, p. 20.

${ }^{10}$ Lobato, 1988, p. 62.

11 Rodríguez y Tordera, 1983, p. 169.

${ }^{12}$ Valbuena Prat, 1927, pp. 3-5. 
sonaje del carretero, hay autorreferencialidad paródica de Calderón cuando habla de La vida es sueño, aunque también se refiere en el mismo tono a otras obras y tópicos de la cultura de su época como $\mathrm{El}$ diablo Cojuelo, también hay parodia del comportamiento de los gallegos y gitanos que interrumpen las visiones del caminante.

Desde el punto de vista espectacular, el inicio de esta mojiganga implica la creación de un espacio extensivo ya que el público, ante el tablado vacío, escucha una canción que viene de fuera del escenario, la cual está acompañada por «música y castañetas e instrumentos»:

\section{Vaya de fiesta, vaya de gira, vaya de baile, vaya de chanza, vaya y venga la mojiganga.}

(Visiones, vv 1-3) 13

La cancioncilla ya implica una autorreferencialidad genérica que establece una distancia con la ficción escénica ya que hace alusión a la mojiganga y a su sentido festivo. La historia de la mojiganga se estructurará a partir de un elemento de verosimilitud: un carretero sale y se alegra que haya terminado la mojiganga (otra que se representa dentro) y con ella la representación y llama al autor de comedias para recriminarle el retraso con están partiendo. El espacio que así se crea es el de la propia representación, o sea el de un corral. Esta primera escena, constituida por el diálogo entre los dos personajes, textualmente ya presenta una inversión paródica del mundo pues el carretero, paradigma de los juramentos (no en balde se dice «jurar como un carretero") insiste en que no quiere jurar, lo cual da a la escena el tono humorístico, el cual está derivado del texto y no de la espectacularidad.

Una vez que concluye la representación (teatro dentro del teatro) a la que alude el Carretero, el diálogo continúa en este doble espacio que ha creado la ficción de la mojiganga, ya que en el espacio escénico del tablado está el exterior, y el interior sería el espacio dramático del propio teatro o el vestuario. Podemos decir que hay una re-

${ }^{13}$ Las citas están tomadas de la edición de Rodríguez y Tordera, 1982. En adelante solamente indico el título abreviado y número de versos. 
presentación espacial realista, en cuanto los espacios son contiguos y lógicos.

Al iniciar el traslado de la compañía, nuevamente el texto involucra la parodia y una suerte de inversión carnavalesca, ya que al indicar el autor cómo deben colocarse los actores en el carro, se refiere a ellos por el personaje que interpretan en un auto sacramental y cuya caracterización conservan, estableciendo una unidad entre personaje y representante y así, con un tono casi de auto sacramental, el Alma debe ir en el mejor lugar (el Carretero, cual personaje de auto, comenta que eso está bien "porque el alma es lo primero", v. 41) y alejada del que es su esposo, en la vida real, que es el Cuerpo (sin olvidar que existe un auto sobre el matrimonio del Cuerpo y el Alma), finalmente el Ángel, interpretado por una mujer, es echado con el Diablo. El Autor, tal vez en un guiño de maestría escénica de Calderón, se despide diciendo:

Autor Con esto me adelanto

que el que algo ve, no desespera tanto

de lo demás que tarda.

(Visiones, vv. 48-50)

La realidad es que el público a continuación no verá nada pues (cosa rara en un tipo de teatro como el del Siglo de Oro que está construido con escenografía de palabras), el escenario queda vacío y el público tiene que reconstruir auditivamente la escena del carro cargado de actores iniciando su camino. La acotación pide «ruido de carretería y campanillas» ${ }^{14}$ (v. 54) y estos ruidos deben ser sinecdóticos y evocar acciones que el espectador pueda identificar sin ninguna duda. Además nuevamente se escucha una canción alusiva a la mojiganga, solo que ahora es realista y verosímil, pues son los actores viajeros que cantan para que el viaje se entretenga. Podemos presuponer, con un mínimo de realismo escénico, que incluso las voces se van alejando para indicar la marcha del carro.

En un cambio espacial sin transición, desaparece como espacio dramático el lugar aledaño al corral o tablado y se crea uno nuevo: el

${ }^{14}$ Este tipo de efectos, aunque se inicia con Lope, realmente toma auge en las obras de Tirso y de Calderón. Ver Recoules, 1975, pp. 144-145. 
medio del camino el cual se construye por la entrada del caminante, identificado como tal por las alforjas y una bota de vino. Nuevamente la comicidad de la representación es textual y con una idea de mundo al revés, pues el Caminante se queja de las cosas obvias que suceden naturalmente, como el hecho que haga calor en junio a medio día, lo cual sirve para que calme los calores, bebiendo vino.

El Caminante bebe y se pone a dormir la siesta, motivo tópico de la construcción entremesil, pues del dormir derivan los sueños y las visiones. Así nuevamente en el escenario no pasa nada, ya no está vacío, pero no hay acción, la acción se desplaza al espacio extensivo, solo que ahora no existe ningún muro o puerta que implique y justifique su existencia. Lo que sucede fuera de la vista del espectador es que llega el carro de comedias y vuelca, y son las voces dentro las que hacen que el espectador construya auditivamente la escena. Así sucede en un juego de palabras:

$\begin{array}{ll}\text { Ángel } & \text { Vuelcos me da el corazón. } \\ \text { CARRetero } & \text { Y al carro le dio lo mesmo: } \\ & \text { volcose con mil demonios. }\end{array}$

(Visiones, vv. 93-95)

Al despertar, el Caminante toma las voces que se oyen fuera por visiones y establece un contrapunto paródico con sus comentarios sobre el cuerpo del Alma, el diablo que se rompe una pierna y es entonces el diablo Cojuelo (muy posible alusión a la obra de Vélez de Guevara), la muerte de la muerte y el ángel descalabrado, que para eso «mejor estuviérase en el cielo...» (v. 110).

A partir de este punto la comicidad regresa al elemento espectacular con la entrada de los personajes alegóricos del auto sacramental que han representado y el contraste con el mundo real del Caminante y así los actores beben alegremente y sus personajes entran en contradicción con su definición. Los diálogos de los personajes en esta escena contienen didascalias implícitas que indican el movimiento o persecución de los personajes, amén de las acotaciones que piden un mundo al revés: «Sale el Demonio, santiguándose»(v. 116); «Saca el Cuerpo el Alma en brazos» (v. 154), la escena no es estática y la comicidad ya no es solo verbal sino gestual con persecuciones incluidas que terminan cuando la Muerte encuentra la bota de vino de la que todos be- 
berán, incluido el Ángel con los consiguientes comentarios del Caminante:
Alma
Por obedecerte bebo.
CAminAnte
Como el alma es tan devota se eleva mirando al cielo. (Visiones, vv. 196-197)

El universo de las visiones del trasmundo del Caminante se rompe con la entrada del Carretero que avisa que el carro ha sido arreglado y la compañía puede continuar el viaje. La explicación de lo que ha sucedido se evita con una nueva situación dramática. Nuevamente hay una doble espacialidad cuando se oye dentro decir:
Gallegos Fugid galegos, que en pos de nos los gitanos ya chegan.

(Visiones, vv. 222-224)

Se plantea una nueva circunstancia con personajes que son lugares comunes de la tradición literaria o del acervo folclórico: segadores gallegos y gitanos ladrones. Los personajes sobre el tablado: los actores caracterizados del auto, crean un espacio diegético, podemos suponer que hablan hacia la parte de atrás del tablado invitando a quienes han hablado fuera a acercarse. La mojiganga termina con el susto de los gallegos y la aclaración que no es un demonio sino la compañía de actores. Nuevamente es el contraste de la ingenuidad, mostrada textualmente, de los gallegos y el movimiento escénico el que da el tono humorístico. Como es de esperar y debido se acaba con el canto y los «instrumentos de mojiganga» (v. 280) que pueden ser castañetas, silbatos, panderillos, guitarra, cornetas, etc.

En esta mojiganga Calderón juega con la referencia paródica y la parodia escénica que une actor-personaje, el contraste de la realidad y la visión y desde luego el tratamiento cómico de los personajes, esto es los personajes se autoparodian, de la misma manera que lo hace Calderón cuando el Caminante dice:

La almohada sobre que estoy durmiendo todavía, pues estoy 
viendo que la vida es sueño.

(Visiones, vv. 181-184)

Tal vez todo el texto se pueda ver como una gran parodia, incluso de los autos sacramentales, pero "The mojiganga does not parody fundamental religius dogma, but rather the theatrical conventions of its presentation» ${ }^{15}$.

Mucho más entremesil y cargada de ironía y sátira y con ello más dramática que espectacular es El pésame de la viuda, en esta mojiganga se critica las costumbres usando el tópico de la viuda que se supone inconsolable, pero que está más cerca de aquel refrán que dice «el muerto al hoyo y el vivo al bollo». Algunos autores como Huerta Calvo $^{16}$ han querido ver en el teatro breve calderoniano una buena dosis de misoginia, pero no parece ser este el caso.Aquí el planteamiento dramático y escénico es muy distinto de lo que sucede en Las visiones de la muerte, aunque se conservan elementos de los paradigmas que caracterizan a la mojiganga y que mencionábamos antes: sobre todo la corporalidad está claramente presente pues el núcleo de la escena representada es el almuerzo de la viuda y quienes la consuelan, ya no es el vino del caminante de la mojiganga anterior, son las damas que deben renunciar al chocolate, impropio del dolor de la viuda doña Clara, y pasar paradójicamente a los mucho más sólidos huevos con torreznos, que se vuelven propios del luto por aquello de «que son duelos y quebrantos» (v. 71). Otro elemento de mojiganga es la transformación de todo el sentido del pésame, transformación que se plasma en el estribillo que reiterativamente se repite a lo largo de toda la pieza: «El diablo pensara / de un pésame hacer una mojiganga».

La representación es desde un principio verosímil y realista; aparece la dama apesadumbrada, con su criada y el escudero en una sala de su casa, el espacio dramático del interior de la casa se crea por las indicaciones a la criada y al escudero sobre la luz que entra y que la dama quiere evitar como expresión de su duelo por lo que manda cerrar

15 Greer, 1995, p. 321. Margaret Greer rastrea una profunda relación entre la mojiganga y el auto sacramental pues acepta la propuesta de María Luisa Lobato (1989, p. 352) a partir del manuscrito BN Ms. 16796 que indica que la mojiganga fue interpretada por Jerónimo de Peñarroja y Mariana de Borja o Mariana Romero, quienes representaron el auto de La vida es sueño en 1673.

16 Huerta Calvo, 1983, p. 810. 
puertas y ventanas. Después están las amigas que la visitan, que entrarían de calle, esto es con mantos, y se sientan, reiterando la interioridad espacial de la casa, y hablan con doña Clara del dolor de la pérdida del «buen Juan». Sin embargo, la escena se va salpicando de comicidad escénica, apoyada en el juego de la luz que va y viene. Aunque es obvio, hay que recordar que esta oscuridad es convencional, pues no variaba la iluminación. Así se justifica que la dama doña Aldonza se siente sobre la salvilla y demás vidrios, que se oculten el plato y las copas bajo la falda. Todo salpicado con la comicidad verbal de los comentarios irónicos del escudero e Isabelilla de este tipo:

$\begin{array}{ll}\text { Aldonza } & \text { Agua es, no importa nada. } \\ \text { EsCudero } & \text { Y más que aunque fuera vino } \\ & \text { no dejara de ser agua. }\end{array}$

(Pésame, vv. 132-134)

La inflexión del tono crítico y humorístico entremesil para pasar el efecto exacerbado de mojiganga se da a partir de la llegada del pretendiente que ha anunciado doña Quiteria. La escena previa es un diálogo de ágil contraste de antítesis de la dama dolorida lamentándose y cambiando rápidamente a preguntas interesadas sobre el pretendiente, mientras las otras damas comen y beben alegremente. A partir de ese momento la comicidad de la mojiganga se apoyará más en la acción escénica. El espacio está oscuro por lo que cuando entran los caballeros don Marcos y don Luis no ven lo que sucede y terminan sentándose de espaldas a las damas, y sobre todo cuando entra el tercer caballero, don Lesmes, que termina cayendo al suelo al no poder ver la silla donde se iba a sentar. Rápidamente se habla del matrimonio entre la viuda y el caballero recién llegado, pero toda la secuencia se rompe cuando la dama manda que traigan a su Juanico y entra el hijo de la viuda caracterizado como "el niño de la Rollona» ${ }^{17}$. La acotación indica: «Sale Morales vestido de Niño de la Rollona con un pan de Vallecas en la mano» (v. 277). Indicación esta última que en su época tenía sentido para indicar lo mimado del niño ya que según los ver-

17 El personaje aparece en otras mojigangas y entremeses de Simón Aguado, Francisco Navarrete y Ribera, Francisco de Avellaneda y algún otro anónimo. FaliuLacourt, 1991, pp. 51-52. 
sos que Tirso de Molina pone en boca Blas en una de sus comedias «El pan de Vallecas es / por branco y sazonado / en Madrid más estimado» ${ }^{18}$.

Este niño es la figura grotesca que recoge la tradición proverbial («El hijo de la Rollona que tiene siete años y mama aun ahora» ${ }^{19}$ ); que la caracterización del personaje tiene que ser grotesca no hay ninguna duda desde que lo interpreta un actor adulto ${ }^{20}$. La presencia de este tipo de niños ridículos en el escenario como un recurso teatral ha sido interpretada ${ }^{21}$ como recreación dramática de una tradición festiva o carnavalesca relacionada con las botargas, seres deformes o monstruosos y la comicidad que deriva del recurso es más por su simple presencia que por lo que dicen o hacen.

En este caso la llegada del Niño de la Rollona es el obstáculo para la boda de la viuda, pero también lo es su reclamación sobre lo que se ha convertido el duelo por el difunto:

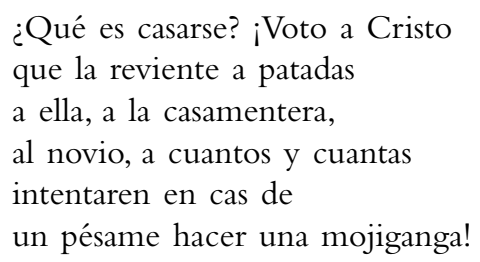

(Pésame, vv. 287-294)

Después de esta entrada, la tensión dramática se suspende y con ella la ficción dramática que se ha construido y viene la canción y baile finales que recalcan cómo se transforma el dolor de hoy en placer de mañana, transformación típica de mojiganga.

Por último veamos la mojiganga de Los guisados la cual corresponde a otro tipo de obra. En ella el paradigma de la naturaleza es el que estructura la pieza, la deformación de los personajes rebasa el ridículo que manda el entremés y se convierte en una deformación con

18 Tirso de Molina, La villana de Vallecas, I, vv. 1127-1129.

19 Correas, Vocabulario de refranes y frases proverbiales, p. 119.

${ }^{20}$ La tabla de personajes indica que el Niño de la Rollona lo representa Morales, posiblemente Jerónimo de Morales, también conocido como Moralón quien hacía papeles de segundo galán o barba en diversas compañías. Ver Ferrer Valls, 2008.

${ }^{21}$ Buezo, 1992, pp. 161-163. 
«una intencionalidad sistemática, pues está regida por la iconicidad, procedimiento semiótico según el cual el signo guarda semejanzas identificables con la cosa significada» ${ }^{22}$. Esta mojiganga tiene un sentido más de fiesta que incluso podría ser palaciega.

La mojiganga se inicia con una escena de tipo entremesil muy verosímil en la cual tres caballeros hablan en un espacio indeterminado pero que puede ser la casa de don Lesmes a la que han llegado los otros dos caballeros. En este primer momento el sentido de la escena es la crítica a quien se siente poeta dramático, pero sólo es un escritor disparatado. La crítica y el humor se derivan del texto, pues nada indica que el poeta disparatado tenga alguna caracterización particular. La escena termina simplemente cuando salen los caballeros y antes de salir dicen:

Los DOS Vamos, fiero ignorante.

Don Lesmes Principio del torneo y adelante.

(Guisados, vv. 33-34)

A partir de lo que sigue el tiempo, el espacio, la realidad todo se transforma, la escena debe representar un mundo de fantasía incluso de absurdo, pero también de burla y ridículo. En realidad Calderón, el dramaturgo, deja la creación del texto espectacular al autor de comedias pues solo pide:

Sale por un lado el Dios Baco con acompañamiento; y por otro lado don Estofado y doña Olla, que estas figuras se pueden hacer o vestirlas ridículamente como suenan o con verdaderas ollas y pucheros, $y$ en cuanto a palenque, teatro $y$ lo demás, como mejor pareciere según los versos y en el medio la música. (Guisados, acot. v. 35)

La comicidad de lo que vendrá será plenamente escénica y dependerá en buena medida de la propia interpretación y caracterización de los actores, el vestuario y la manera en que se escenifica el torneo entre los distintos personajes-guisos: Estofado, Gigote, Carnero verde, Carnero asado y sus damas: la Olla, Albondiguilla, Pepitoria y Ensalada, y con el vulgar intruso, extraño entre tantos platos de refinamiento y

22 Rodríguez y Tordera, 1983, p. 65. 
valoración, el popular Menudo — don Mondongo- y su dama doña Chanfaina Livianos.

La risa surge precisamente de la exageración conceptual, despropósito gastronómico de hacer de los guisados damas y caballeros, y por tanto, tener discursos heroicos y de pretendida nobleza y combatir efectivamente con cucharas y rajas de canela ante el dios Baco, personaje de larga y clásica tradición, a quien acompañan, con su linaje popular y rústico, la cocinera gallega y el galopín asturiano.

La burla hacia el escritor de comedias queda en segundo plano ante la parodia gastronómica del torneo caballeresco. La obra de teatro se convierte esencialmente en un espectáculo visual en el cual la caracterización será el contrapunto y disparador de la comicidad. Como es de esperar el final es cantado:

BACO Teneos, ¿no veis que soy Baco $\mathrm{y}$ a todos presido?

ToDOS

Pues

¿qué, qué queréis?

BACO

Que pues estamos

en forma de mojiganga

se fenezca esto cantando.

(Guisados, vv. 214-219)

Y quienes canten serán doña Olla y don Estofado. No hay que olvidar que a fin de cuentas

Las figuras de la mojiganga, extraídas de los desfiles callejeros, rozan a menudo lo estrafalario y lo dejan bien visible por medio de un vestuario que se puede calificar de icónico, lo mismo puede decirse de los complementos que identifican al personaje, capaz todo ello de presentar ante los ojos del espectador lugares, alimentos, abstracciones alegóricas, mitos, razas diversas o figuras de la tradición literaria y personajes del folclor ${ }^{23}$.

Por lo visto hasta aquí es clara la amplitud de lo que entendemos como mojiganga, pues sin menoscabo de unos principios generales, en la realización concreta las posibilidades son muchas y Calderón las

${ }^{23}$ Lobato, 2000, p. 19. 
explota con gran dominio de la técnica. En primer lugar el género une, ya que se trata de obras cómicas, la comicidad textual y la comicidad escénica, la primera muy relacionada con arte de ingenio, característico de la mentalidad barroco, y la burla especialmente paródica, y la segunda más en consonancia con la comicidad de la comedia del arte, en la que no están ausentes caídas, palos y persecuciones.

Por otra parte la técnica teatral de Calderón va desde la minificción crítica de tono entremesil, pero con todos los elementos tradicionales y bien probados de entradas y salidas, espacios interiores, etc. tal como sucede en la comedia, hasta un cierto grado de experimentalismo con escenario vacío, construcción diegética por medio de efectos sonoros.

Indudablemente la parodia es un mecanismo que Calderón utiliza con gran habilidad en muy distintas perspectivas pues los hace textualmente cuando parodia las referencias culturales (en las que incluye sus propias obras), parodia los usos de representación, tanto desde sus elementos esenciales (identidad personaje-actor), como desde sus convenciones (el propio experimentalismo del escenario vacío). Pero la parodia también es escénica, en grado máximo en el torneo de los guisados, pero también en la caracterización de los personajes (el Diablo que asustado se santigua o el Ángel que enojado entra con una cruz).

El uso de los tópicos, sean estos verbales a partir de refranes o frases hechas o de personajes y situaciones teatrales, se transforma por el ingenio y se lleva al extremo sin pretender que se pierda de vista que se trata de un tópico y por tanto lugar común conocido.

Lo más importante en la construcción de la mojiganga calderoniana tal vez sea la relación esencial y profunda que existe entre el plano textual — discurso dramático- y el plano espacial — discurso espectacular- En esta doble discursividad se puede privilegiar una de ellas, alternarlas o ponerlas a funcionar simultáneamente con posibilidades armónicas o antitéticas, pero sin olvidar que en el compacto espacio del teatro breve esta doble discursividad alcanza una gran intensidad por su condensación. La mojiganga en un sentido está apelando para poder funcionar plenamente a la prenotoriedad que tiene el espectador de sus referentes.

Tomando en cuenta lo que planteábamos al principio estos elementos no son exclusivos de la mojiganga sino que se extiende a las 
otras formas cómicas breves, es posiblemente un problema de intensidad, lo cual hace que haya ejemplos muy claros de obras que se adscriben a un género, pero también muchos otros fronterizos. No se trata «de expandir lo teatral sin fronteras ni límites, lo que sólo añadiría confusión, sino de recuperar para el ámbito dramatúrgico, en una suerte de órbitas concéntricas, una serie de manifestaciones que de forma habitual vienen siendo excluidas del espectáculo teatral» ${ }^{23}$.

${ }^{23}$ Díez Borque, 1996, p. 68. 


\section{Bibliografía}

Arellano, I., «El texto de los entremeses de Calderón. Problemas ecdóticos y hermeneúticos», Romance Quarterly, 60, núm. 1, 2013, pp. 12-29.

Asensio, E., Itinerario del entremés, Madrid, Gredos, 1971.

Buezo, C., «El niño ridículo en el teatro breve, plasmación dramática de una práctica festiva», Criticón, 56, 1992, pp. 161-178.

- La mojiganga dramática. De la fiesta al teatro. I Estudio, Kassel, Reichenberger, 1993.

- Prácticas festivas en el teatro breve del siglo XVII, Kassel, Reichenberger, 2004.

Calderón de la Barca, P., Entremeses, jácaras y mojigangas, ed. E. Rodríguez y A. Tordera, Madrid, Castalia, 1982.

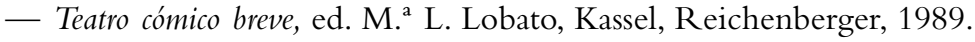

- Una fiesta sacramental barroca: Loa para el auto "Entremés de los instrumentos»; Auto Sacramental "La segunda esposa y triunfar muriendo»; Mojiganga de "Las visiones de la muerte», ed. J. M. ${ }^{a}$ Díez Borque, Madrid, Taurus, 1984.

Correas, G., Vocabulario de refranes y frases proverbiales (1627), ed. L. Combet, Bordeaux, Université de Bordeaux, 1967.

Díez Borque, J. M. a, Teoría, forma y función del teatro español de los Siglos de Oro, Palma de Mallorca, José J. Olañeta, 1996.

Faliu-Lacourt, C., «El Niño de la Rollona», Criticón, 51, 1991, pp. 51-56.

Ferrer Valls, T. (dir.), Diccionario biográfico de actores del teatro clásico español (DICAT), Kassel, Reichenberger, 2008.

GonzÁlez, A., «La comicidad escénica en el teatro breve calderoniano: La casa holgona, Las Carnestolendas y La garapiña», en Otro Calderón. Homenaje a Maria Teresa Cattaneo, ed. A. Cassol y J. M. Escudero, Anuario Calderoniano, 3, 2010, pp. 155-172.

Granja, A. de la, Entremeses y mojigangas de Calderón para sus autos sacramentales, Granada, Universidad de Granada, 1982.

— «Doña Bárbula "convida": texto, fecha y circunstancia de una mojiganga desconocida de Calderón", Criticón, 37, 1987, pp. 117-168.

Greer, M. R., «La vida es sueño ¿o risa?: Calderón parodies the auto», Bulletin of Hispanic Studies, 72, 1995, pp. 313-325.

Huerta Calvo, J., «El discurso popular en el siglo Xvir. Calderón y los géneros teatrales ínfimos», en Calderón: actas del Congreso Internacional sobre Calderón y el teatro español del Siglo de Oro, ed. L. García Lorenzo, Madrid, Consejo Superior de Investigaciones Científicas, 1983, vol. II, pp. 805816.

- El nuevo mundo de la risa. Estudios sobre el teatro breve y la comicidad en los Siglos de Oro, Palma de Mallorca, José J. Olañeta, 1995.

Lobato, M. ${ }^{a}$ L., "El escolar y el soldado: Entremés inédito de Calderón, para el auto ¿Quién hallará mujer fuerte?», Castilla, 13, 1988, pp. 61-78. 
— «La mojiganga», Ínsula: Revista de Letras y Ciencias Humanas, 639-640, 2000, pp. 15 y $18-20$.

Molina, T., La villana de Vallecas, ed. S. Eiroa, Pamplona, Universidad de Navarra / Instituto de Estudios Tirsianos, 2001.

Plata, F., «Mundinovos y espejos deformantes: el mundo al revés en una mojiganga inédita de Calderón», Criticón, 106, 2009, pp. 161-192.

Recoules, H., «Ruidos y efectos sonoros en el teatro español del Siglo de Oro», Boletín de la Real Academia Española, 55, 1975, pp. 109-145.

Rodríguez, E. y A. Tordera, Calderón y la obra corta dramática del siglo XVII, London, Tamesis, 1983.

Tordera, A., "Historia y mojiganga del teatro", en Actas de las jornadas sobre teatro popular en España, ed. J. Álvarez Barrientos y A. Cea, Madrid, Consejo Superior de Investigaciones Científicas, 1987, pp. 249-288.

Valbuena Prat, A., Las visiones de la muerte, Madrid / Paris / Buenos Aires, Agrupación de Amigos del Libro de Arte, 1927. 